\title{
Como eu faço: Cardioplegia sangüínea isotérmica retrógrada de baixo volume
}

\author{
Domingo M. BRAILE*
}

\section{RBCCV 44205-183}

\author{
BRAILE, D. M. - Como eu faço. Cardioplegia sangūínea isotérmica retrógrada de baixo volume. Rev. Bras. \\ Cir. Cardiovasc., 7(3):221-229, 1992. \\ DESCRITORES: proteção miocárdica, cardioplegia.
}

\begin{abstract}
O desenvolvimento de métodos de proteção e ressuscitação miocárdica tem evoluído de forma rápida e consistente, nos últimos anos, principalmente devido ao estabelecimento de bases fundamentais para o entendimento do metabolismo cardíaco e técnicas que permitam seu emprego de maneira eficiente e prática.
\end{abstract}

Alguns pontos ficaram bem estabelecidos e devem ser do conhecimento dos cirurgiōes.

1 O metabolismo cardíaco é fundamentalmente aeróbio, dependendo, portanto, do fornecimento contínuo de oxigênio e substratos.

2 O músculo cardíaco converte energia química em trabalho mecânico com baixa taxa de conversão.

Gasta 9,8 watts de energia química para produzir 1,2 watts de trabalho mecânico com eficiência de apenas $15 \%$ (característica dos motores químicos).

3 O miocárdio, apesar de ter uma reserva de 200 $\mathrm{mg}$ a $300 \mathrm{mg}$ de ATP, devido ao elevado consumo, necessita de grande e contínua produção dos fosfatos de alta energia, ao desenvolver trabalho mecânico. Para isso, o coração produz e utiliza $35 \mathrm{~kg}$ (ou $35.000 .000 \mathrm{mg}$ ) de ATP por dia ${ }^{7}$.

4 Em relação ao gasto de energia, o coração é um órgăo peculiar, consome $90 \%$ da energia para desenvolver trabalho eletromecânico e apenas $10 \%$ para manter a homeostasia e a viabilidade dos tecidos ${ }^{1}$.

5 O metabolismo miocárdico tem melhor desempenho em temperaturas normais do organismo humano $\left(36^{\circ} \mathrm{C}\right)$ com adequado funcionamento de mitocôndrias, bombas de sódio, potássio e cálcio, sistemas enzimáticos, tampōes, removedores (scavengers) etc.

6 O frio diminui o consumo de energia pelo miocárdio, mas, ao mesmo tempo, diminui a sua produção.

Além disso, impedindo o funcionamento da bomba de cálcio, eleva a concentração do mesmo no citosol, aumenta a tensão da parede ${ }^{\circ}$, podendo aumentar o consumo. O coração, desenvolvendo trabalho mecânico em baixa temperatura, gasta mais energia que em normotermia '.

7 A hipotermia em coraçōes parados leva a pequena economia de energia ${ }^{4}$. 8 . Assim, o coração:

a) trabalhando em normotermia consome $9 \mathrm{ml}$ O/ $100 \mathrm{~g}$ de miocárdio;

b) parado em normotermia consome $1 \mathrm{ml} \mathrm{O} / 100$ g de miocárdio;

c) parado em hipotermia $22^{\circ} \mathrm{C}$ consome $0,3 \mathrm{ml}$ $\mathrm{O}_{2} / 100 \mathrm{~g}$ de miocárdio;

Trabalho realizado no Serviço dè Cirurgia Cardíaca - Hospital Beneficência Portuguesa, Hospital IELAR - Cárdio e Hospital de Base/FUNFARME * Do Serviço de Cirurgia Cardíaca - Hospital Beneficência Portuguesa, Hospital IELAR - Cárdio e Hospital de Base/FUNFARME, da Faculdade de Medicina de Sāo José do Rio Preto e Faculdade de Medicina de Catanduva, SP, Brasil.

Recebido para publicaçáo em 2 de dezembro de 1992.

Endereço para separatas: Domingo M. Braile. Av. Juscelino Kubitschek 31011. 15091 Sảo José do Rio Preto, SP, Brasil. 
d) parado em hipotermia $15^{\circ} \mathrm{C} 0,27 \mathrm{ml} \mathrm{O}_{2} / 100 \mathrm{~g}$ de miocárdio.

Se a freqüência cardíaca fosse normalizada, o consumo de $\mathrm{O}_{2}$ aumentaria nos coraçōes hipotérmicos.

Assim, se considerarmos a freqüência normalizada em $120 \mathrm{bat} / \mathrm{min}$, o consumo de $\mathrm{O}_{2}$ em normotermia é de $9 \mathrm{mlO}_{2} / 100 \mathrm{~g}$ de miocárdio. $\mathrm{Na}$ temperatura de $10^{\circ} \mathrm{C}$ na nossa freqüência o consumo é de $20 \mathrm{mlO}_{2} / 100 \mathrm{~g}$.

8 O fluxo coronário normal é de aproximadamente $100 \mathrm{ml}$ por $100 \mathrm{~g}$ de miocárdio, dos quais $90 \mathrm{ml}$ são empregados para desenvolver trabalho eletromecânico e $10 \mathrm{ml}$ para manutenção da viabilidade tecidual.

Desta forma, se o coração estiver parado, necessita-se de apenas $10 \mathrm{ml}$ por $100 \mathrm{~g}$ de miocárdio de fluxo anterógrado ou retrógrado para manter a viabilidade miocárdica. Considerando-se um coração com $300 \mathrm{~g}$, necessita-se de um fluxo contínuo de apenas $30 \mathrm{ml}$ de sangue oxigenado adicionado de agentes, que permita manter o coração despolarizado e, portanto, parado para que as necessidades do metabolismo aeróbio sejam satisfeitas.

9 A adição de aminoácidos como glutamato e aspartato pode melhorar a eficiência metabólica do miocárdio ${ }^{3,}{ }^{10}$, repondo déficits de energia e levando à recuperação anatômica e funcional do músculo cardíaco, que de outra forma estaria condenado ao dano irreversível e à necrose.

10 A via retrógrada, através da infusāo cardioplégica pelo seio coronário com aorta drenada, tem-se mostrado prática e eficiente, permitindo o uso de cardioplegia contínua sem grandes transtornos $1,2,5$.

A distribuição da cardioplegia retrógrada é meIhor que a da via anterógrada, principalmente nos pacientes coronarianos, quando realizada em isotermia com fluxos adequados, controle absoluto das condiçōes de infusão (evitando-se perdas em torno da cânula do seio coronário) e avaliação permanente do débito de oxigênio pela saturaçāo do efluente pela raiz da aorta.

11 Interrupçăo de 3 minutos mesmo em normotermia parace não produzir lesōes quando o coração está parado; contudo, interrupçōes (de 5 minutos) quando ultrapassam 15 minutos no total, provocam déficit contrátil no pós-operatório ${ }^{\circ}$.

12 Todos os métodos de proteçāo miocárdica buscam preservar a função cardíaca durante o período de atuação sobre o coração ou clampeamento aórtico. De acordo com o método ou as condiçōes do miocárdio, podem ocorrer lesōes abaixo do limite de deteç̧āo ou, ainda, lesōes reversíveis e irreversíveis.

Devem ser considerados como especiais os coraçōes que têm grandes déficits de energia, assim como os isquêmicos, hipertróficos, dilatados, cianóticos e imaturos. Cada um deles possui características próprias e podem ou não resistir a um período menor ou maior de isquemia, com diferentes métodos de cardioplegia hipotérmica ou normotérmica, interrompida ou contínua, modificada ou não por aminoácidos etc.

13 Os métodos que compreendem o clampeamento aórtico intermitente e a cardioplegia interrompida admitem períodos de isquemia, com os conseqüentes períodos de reperfusāo.

A reperfusão é uma fase crítica para o miocárdio, uma vez que o coração deverá recuperar os déficits e produzir trabalho eletromecânico com grande consumo de energia, justamente na fase em que mais necessita dela.

Quando se utiliza a perfusão contínua isotérmica anterógrada ou retrógrada não existe isquemia $e$ o período de clampeamento aórtico pode ser entendido mais como um período de ressuscitação cardíaca ${ }^{10} \mathrm{do}$ que um período de dano miocárdico. Isto principalmente se a temperatura e o fluxo sangüíneo forem mantidos em níveis adequados, de tal forma que o metabolismo básico seja suficiente para o fornecimento de fosfatos de alta energia.

14 fluxo da cardioplegia depende da necessidade de substratos e oxigênio durante a parada cardíaca em isotermia, conseqüente à condiçāo prévia do miocárdio e do seu consumo durante o clampeamento aórtico. Quanto mais isquêmico ou mais hipertrófico for o coração, maior fluxo de cardioplegia será necessário para manter a viabilidade ou recuperar os déficits de energia existentes.

15 Poderíamos fazer uma comparaçāo que, embora grosseira, nos faria entender melhor os conceitos aqui admitidos.

Comparemos o coração ao motor de um automóvel, os fosfatos de alta energia à carga de sua bateria e os substratos ao combustível (álcool, por exemplo).

Ao estacionar o automóvel, poderemos:

a) Parar o motor, fechando o fornecimento de combustível (clampeamento aórtico) sem desligar a chave (ignição). O motor vai parar por ter consumido todo o substrato (álcool) disponível no carburador e tubulaçōes. Não há produção de energia; a bateria vai manter a carga que já tinha ou perder certa quantidade, dependendo do eventual consumo elétrico (tensão da parede do ventrículo por inibição 

BRAILE, D. M. - Como eu faço: Cardioplegia sangūínea isotérmica retrógrada de baixo volume. Rev. Bras. Cir. Cardiovasc., 7(3):
221-229, 1992.

da bomba de cálcio). Se tinha pouca carga ou a perdeu (déficit de ATP), estará com pouca energia para nova partida do motor.

No momento da partida, principalmente se o motor estiver frio, necessitará de muita energia da bateria para fazer o motor girar, bombear álcool, encher o carburador e fazer o motor "pegar". Se a bateria estiver "fraca", o motor dará algumas voltas, a bateria se esgotará e nāo será possível fazê-lo funcionar, a nāo ser que se restaure a energia da bateria. Isto é conseguido através de: 1) reperfusão modificada controlada; 2) assistência circulatória por horas, dias ou semanas (extracorpórea prolongada, balāo intra-aórtico, coração artificial etc.), com as graves conseqüências que conhecemos e que levam a alta mortalidade.

b) Parar o motor, desligando a chave (ignição) (cardioplegia potássica hipotérmica). O motor pára e fica frio, com conservaçāo de certa quantidade de substrato (o carburador fica cheio de álcool). Não existe produção de energia e o consumo é baixo. Porém, com motor parado a bateria não pode carregar-se. Durante este período, pode haver tentativa de fornecer combustível para o motor, mas, estando o mesmo "parado" e "frio", nāo se consegue produzir energia (cardioplegia fria intermitente). No momento da partida, apesar de existir combustível, há pouca energia na bateria e o motor pode "pegar" ou não, dependendo das suas condiçōes e das condiçōes prévias da bateria. Da mesma forma que no caso anterior, pode-se tentar: 1) reperfusāo assistólica modificada quente; 2) assistência circulatória prolongada com circulaçāo extracorpórea (CEC), balāo intra-aórtico, coraçāo artificial etc. por horas, dias ou semanas, até o coraçāo "pegar" ou, no caso da nossa comparação, abandonar o automóvel na estrada (morte).

c) Manter o motor em marcha lenta aquecido (despolarização e parada dos batimentos cardíacos em isotermia) com fornecimento de pequena quantidade de combustível (substratos). Isto deve ser feito de tal forma que o consumo seja pequeno e que a produção de energia seja suficiente para não só manter a carga da bateria, como também aumentá-la (melhorando a eficiência da produção de ATP, com modificaçăo do substrato por adiçāo de glutamato, aspartato etc.), levando à ressuscitaçāo cardíaca. No momento da partida, nada teremos a fazer senāo simplesmente aumentar o fornecimento de combustível (desclampeamento aórtico) e o motor voltará a funcionar plenamente, movendo o auto- móvel de forma eficiente para alegria de todos!!! (saída de CEC com boa performance hemodinâmica sem arritmias e sem o uso de drogas cardioativas).

\section{Técnica}

Baseados nos princípios acima descritos, desenvolvemos a técnica de cardioplegia sangüínea isotérmica retrógrada contínua com emprego de sangue modificado por cloreto de potássio e cloreto de magnésio e melhorado pela adiçāo de glutamato e aspartato.

O sangue para a retroperfusāo é bombeado por bomba de roletes e modificado pela adiçāo de baixo volume de soluçōes altamente concentradas, de forma contínua com utilização de uma seringa elétrica de infusão de alta precisāo.

Descreveremos nos parágrafos seguintes a técnica:

1 A CEC é estabelecida com canulação de ambas as cavas.

O priming do oxigenador deve ser constituído de Ronger Lactato e sangue, quando necessário, para que o hematócrito nāo seja inferior a $25 \%$. O equilíbrio ácido-básico e hidrossalino deve ser rigorosamente controlado, uma vez que o sangue será o principal componente da cardioplegia. Espera-se, assim, que o BE esteja próximo de zero e que o potássio fique em torno de $5 \mathrm{mEq} / \mathrm{l}$. A adiçāo de drogas como manitol, vitamina $\mathrm{C}$, corticosteróides, xilocaína, papaverina etc., no conteúdo do oxigenador, fará parte da própria cardioplegia, no sentido de funcionar como removedores de radicais livres, antioxidantes, estabilizadores de membrana e vasodilatadores coronários, respectivamente.

2 Uma linha de 1/4" tem origem na saída dos oxigenadores de bolhas ou no shunt dos oxigenadores de membrana, levando sangue oxigenado com destino a uma bomba de roletes que permita fluxos estáveis e precisos, entre $50 \mathrm{ml}$ e $500 \mathrm{ml}$ por minuto com controle linear.

Desta bomba, parte uma linha também de 1/4", conectando-se através de um $Y$ com uma linha de $1 / 8^{\prime \prime}$ vindo de uma seringa injetora elétrica, que fornecerá a solução "mãe" da cardioplegia concentrada com baixo volume. Após o Y, a linha de 1/4" passa por um pequeno trocador de calor, que tem também a funçāo de misturar as soluçōes e reter eventuais bolhas. Do trocador de calor, a linha de $1 / 4$ " atinge o campo operatório para ser conectada às cânulas de infusāo anterógrada e/ou retrógrada de cardioplegia. 
BRAILE, D. M. - Como eu faço: Cardioplegia sangüínea isotérmica retrógrada de baixo volume. Rev. Bras. Cir. Cardiovasc., 7(3): 221-229, 1992

3 As soluçōes "măe" apresentam duas concentraçōes, sendo a primeira mais concentrada e chamada soluçāo "māe" de induçăo; a segunda, menos concentrada, denomina-se soluçāo "māe" de manutençāo/reperfusāo.

a) A composiçāo da soluçāo "māe" de induçāo é a seguinte:

Cloreto de potássio

Cloreto de magnésio

Glutamato de sódio

Aspartato de sódio

Água bidestilada q.s.p.

$100 \mathrm{mEq}$
$40 \mathrm{mEq}$
$60 \mathrm{mmol}$
$60 \mathrm{mmol}$
$50 \mathrm{ml}$

As concentraçōes serāo, respectivamente: Cloreto de potássio $2 \mathrm{mEq} / \mathrm{ml}$ ou $2000 \mathrm{mEq} / \mathrm{l}$ Cloreto de magnésio $0,8 \mathrm{mEq} / \mathrm{ml}$ ou $800 \mathrm{mEq} / \mathrm{l}$ Glutamato de sódio $\quad 1,2 \mathrm{mmol} / \mathrm{ml}$ ou $1200 \mathrm{mmol} / \mathrm{l}$ Aspartato de sódio $\quad 1,2 \mathrm{mmol} / \mathrm{ml}$ ou $1200 \mathrm{mmol} / \mathrm{l}$

b) A composiçāo da soluçăo "māe" de manutençāo/reperfusāo é a seguinte:

Cloreto de potássio

Cloreto de magnésio

Glutamato de sódio

Aspartato de sódio

Água bidestilada q.s.p.

$37,5 \mathrm{mEq}$

$15,0 \mathrm{mEq}$

$60 \mathrm{mmol}$

$60 \mathrm{mmol}$

$50 \mathrm{ml}$

As concentraçōes serāo, respectivamente:

Cloreto de potássio $\quad 0,75 \mathrm{mEq} / \mathrm{ml}$ ou $750 \mathrm{mE} / \mathrm{ml}$

Cloreto de magnésio $0,30 \mathrm{mEq} / \mathrm{ml}$ ou $300 \mathrm{mEq} / \mathrm{l}$

Glutamato de sódio $\quad 1,2 \mathrm{mmol} / \mathrm{ml}$ ou $1200 \mathrm{mmol} / \mathrm{l}$

Aspartato de sódio $\quad 1,2 \mathrm{mmol} / \mathrm{ml}$ ou $1200 \mathrm{mmol} / \mathrm{l}$

Ambas as soluçōes sāo preparadas com sais pró-análise e água bidestilada livre de pirogênio, sendo filtradas em filtro de 0,22 micrômetros, embaladas em frasco âmbar e esterilizadas em autoclave e rotuladas.
4 Cálculos da proporçăo de sangue do oxigenador e soluçōes "māe" de indução e manutenção/ reperfusāo para obtenção das concentraçōes adequadas de cardioplegia final.

A concentraçāo das soluçōes foi calculada de tal forma que a proporção entre solução "māe" e sangue seja sempre de $1 \%$. Desta forma:
Fluxo de bomba de roletes da cardioplegia $50 \mathrm{ml} / \mathrm{min}$ $100 \mathrm{ml} / \mathrm{min}$ $150 \mathrm{ml} / \mathrm{min}$ $200 \mathrm{ml} / \mathrm{min}$ $250 \mathrm{ml} / \mathrm{min}$ $300 \mathrm{ml} / \mathrm{min}$

\section{Fluxo da seringa} injetora

$0,5 \mathrm{ml} / \mathrm{min}$ ou $30 \mathrm{ml} / \mathrm{h}$ $1,0 \mathrm{ml} / \mathrm{min}$ ou $60 \mathrm{ml} / \mathrm{h}$ $1,5 \mathrm{ml} / \mathrm{min}$ ou $90 \mathrm{ml} / \mathrm{h}$ $2,0 \mathrm{ml} / \mathrm{min}$ ou $120 \mathrm{ml} / \mathrm{h}$ $2,5 \mathrm{ml} / \mathrm{min}$ ou $150 \mathrm{ml} / \mathrm{h}$ $3,0 \mathrm{ml} / \mathrm{min}$ ou $180 \mathrm{ml} / \mathrm{h}$
5 Demonstraçăo da concentração final de potássio:

a) Induçāo (Gráfico 1)

Admite-se uma concentraçāo de potássio no sangue de $5 \mathrm{mEq} / \mathrm{l}$.

b) Manutenção/Reperfusāo (Gráfico 2)

Admite-se uma concentração de potássio no sangue de $5 \mathrm{mEq} / \mathrm{l}$

c) Os mesmos cálculos valem para o magnésio, o glutamato e o aspartato.

d) Para volumes diferentes de sangue $(50,100$, 150,200 ou $300 \mathrm{ml}$ por minuto), os cálculos também são os mesmos. (Gráfico 3 )

6 Durante o preparo do circuito da CEC, o sistema da cardioplegia é também preenchido com - priming do oxigenador e com a solução "mãe" de indução, na proporção adequada pelo acionamento da bomba de roletes da cardioplegia e da seringa injetora com a solução de indução

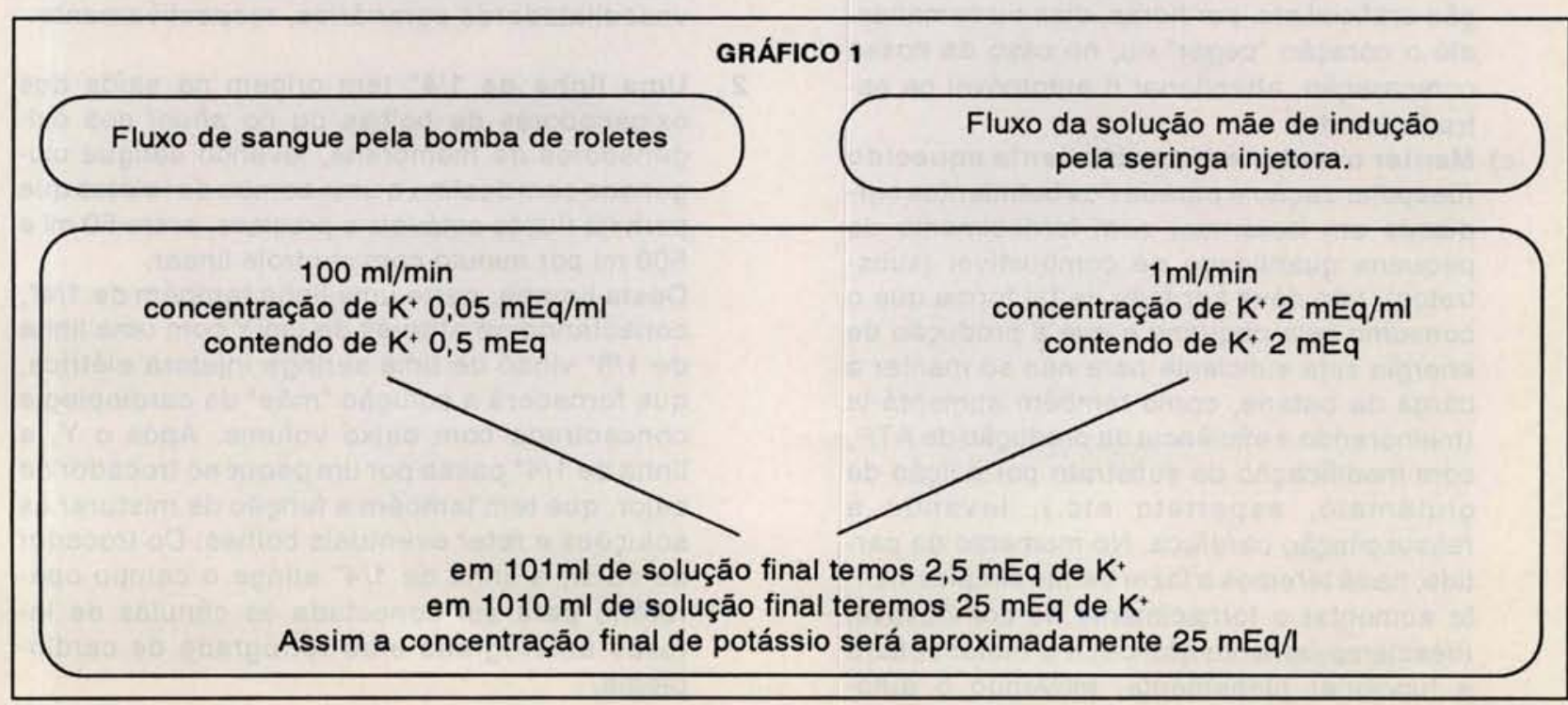



BRAILE, D. M. - Como eu faço: Cardioplegia sangüínea isotérmica retrógrada de baixo volume. Rev. Bras. Cir. Cardiovasc., 7(3):
$221-229,1992$.

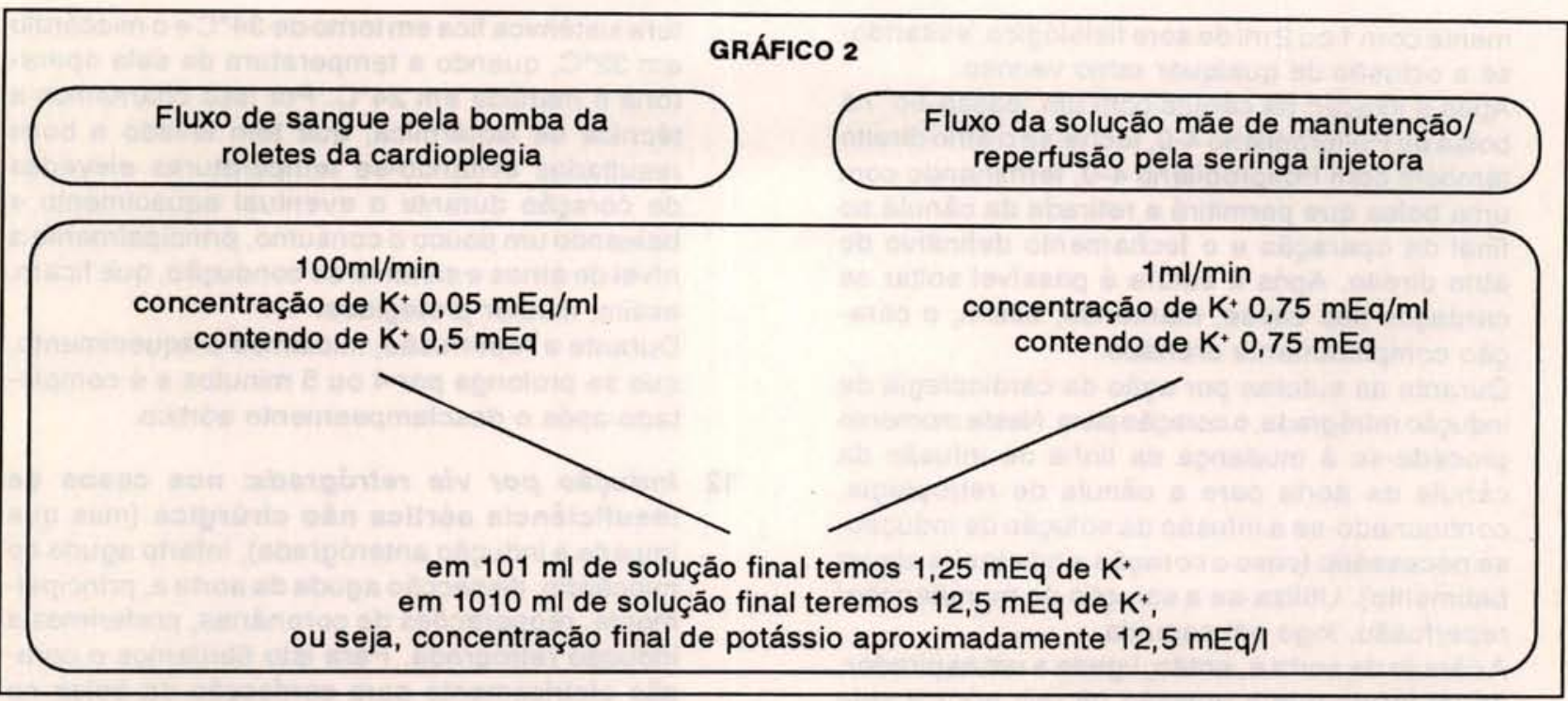

7 Após a entrada em CEC, o priming do sistema de cardioplegia é desprezado de tal forma que tenhamos na linha da cardioplegia a proporção correta de sangue e solução "mãe" de indụção, com concentração final de $\mathrm{K}^{+}$de aproximadamente $25 \mathrm{mEq}$ e concentraçōes adequadas de magnésio e glutamato aspartato, pelo acionamento da bomba de roletes da cardioplegia e da seringa de infusão na proporção correta.

8 Conecta-se a linha de infusāo da cardioplegia com uma cânula $12 \mathrm{~F}$ previamente introduzida na raiz da aorta. Após o clampeamento da aorta, inicia-se a infusão da cardioplegia de indução anterógrada, que deverá ser mantida até a pa- rada completa dos batimentos cardíacos. Neste tempo, ajustam-se os cadarços das cavas e abre-se o átrio direito, através de pequena incisão vertical $2,0 \mathrm{~cm}$ acima da desembocadura da cava inferior. Coloca-se um aspirador no seio coronário e retiram-se, se necessário, os restos da vávula do mesmo que possa impedir a livre colocação da cânula de retroperfusão.

Confecciona-se uma ampla sutura em bolsa na borda do seio coronário com fio de Polipropileno 4-0, introduzindo-se uma sonda de Foley de $12 \mathrm{~F}$ a 20F, de acordo com o diâmetro do seio. Para maior facilidade do fluxo, a ponta da sonda é cortada e a mesma introduzida $1 \mathrm{~cm}$ a $1,5 \mathrm{~cm}$ na luz do seio coronário. $O$ balāo é insuflado leve-

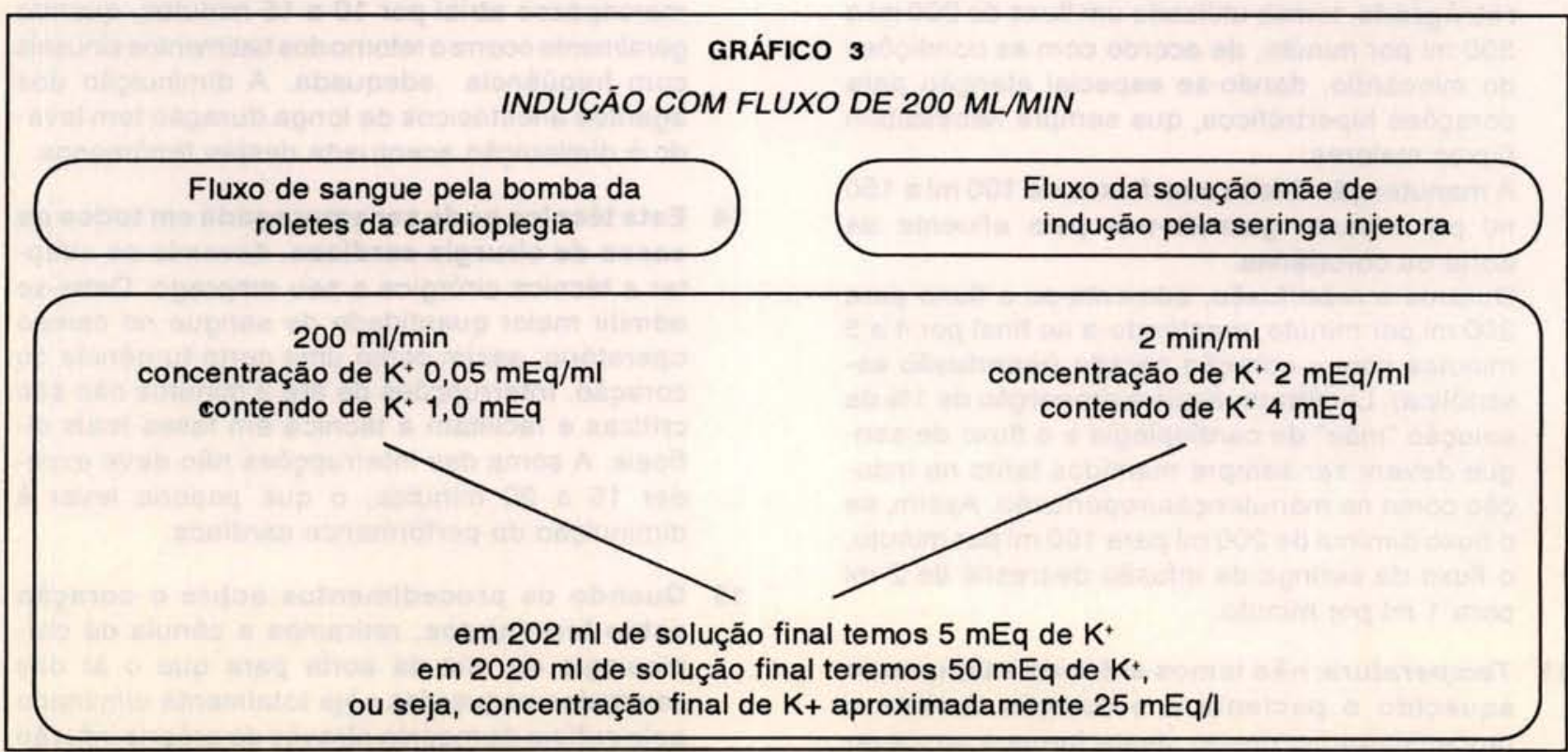


mente com 1 ou $2 \mathrm{ml}$ de soro fisiológico, evitandose a oclusão de qualquer ramo venoso.

Após a fixação da cânula com um "passa-fio" na bolsa de Polipropileno 4-0, fecha-se o átrio direito também com Polipropileno 4-0, terminando com uma bolsa que permitirá a retirada da cânula ao final da operação e o fechamento definitivo do átrio direito. Após a sutura é possível soltar os cardaços das cavas, mantendo, assim, o coraçăo completamente drenado.

Durante as suturas por ação da cardioplegia de indução retrógrada, o coração pára. Neste momento procede-se à mudança da linha de infusão da cânula da aorta para a cânula de retroplegia, continunado-se a infusão da solução de indução, se necessário (caso o coração ainda tenha algum batimento). Utiliza-se a soluçāo de manutenção/ reperfusão, logo em seguida.

A cânula da aorta é, entăo, ligada a um aspirador, de tal forma que a pressão na raiz aórtica seja zero ou negativa.

As observaçōes do enchimento venoso e da saturação do efluente pela aorta são fundamentais neste ponto e durante toda a evolução da operaçāo.

A saturação do efluente deve ser mantida acima de $60 \%$ ou $30 \mathrm{mmHg}$ de pressão parcial de $\mathrm{O}_{2}$. Se estimar-se uma saturaçāo menor, a cânula deve ser reposicionada ou o fluxo aumentado.

9 Após 5 minutos de induçăo, passa-se para a soluçāo de manutenção/reperfusāo. Para isto, troca-se a seringa no aparelho de infusão. A utilização de uma torneira de três vias facilita a manobra.

10 Fluxos: durante a indução anterógrada ou retrógrada, temos utilizado um fluxo de $200 \mathrm{mla}$ $300 \mathrm{ml}$ por minuto, de acordo com as condiçōes do miocárdio, dando-se especial atençāo para coraçōes hipertróficos, que sempre necessitam fluxos maiores.

A manutenção é feita com fluxos de $100 \mathrm{ml}$ a 150 $\mathrm{ml}$ por minuto, guiando-nos pelo efluente da aorta ou coronárias.

Durante a reperfusão, aumenta-se o fluxo para $200 \mathrm{ml}$ por minuto, mantendo-a ao final por 4 a 5 minutos com o coração parado (reperfusāo assistólica). Lembramos que a proporção de $1 \%$ da solução "māe" de cardioplegia e o fluxo de sangue devem ser sempre mantidos tanto na indução como na manutenção/reperfusão. Assim, se o fluxo diminui de $200 \mathrm{ml}$ para $100 \mathrm{ml}$ por minuto, o fluxo da seringa de infusão decresce de $2 \mathrm{ml}$ para $1 \mathrm{ml}$ por minuto.

11 Temperatura: náo temos esfriado e tampouco aquecido o paciente e o coração durante o procedimento cirúrgico; desta forma a tempera- tura sistêmica fica em torno de $34^{\circ} \mathrm{C}$ e o miocárdio em $32^{\circ} \mathrm{C}$, quando a temperatura da sala operatória é mantida em $24^{\circ} \mathrm{C}$. Por isso chamamos a técnica de isotérmica, que tem levado a bons resultados evitando-se temperaturas elevadas do coração durante o eventual aquecimento e baixando um pouco o consumo, principalmente a nível de átrios e sistema de condução, que ficam, assim, melhor protegidos.

Durante a reperfusāo, iniciamos o aquecimento, que se prolonga por 4 ou 5 minutos e é completado após o desclampeamento aórtico.

12 Indução por via retrógrada: nos casos de insuficiência aórtica não cirúrgica (mas que impede $a$ indução anterógrada), infarto agudo do miocárdio, dissecção aguda da aorta e, principalmente, reoperaçōes de coronárias, preferimos a indução retrógrada. Para isto fibrilamos o coração eletricamente para confecção da bolsa no seio coronário, iniciamos a retroplegia e clampeamos a aorta.

13 Anestesia: devemos recordar-nos de que os agentes anestésicos introduzidos no sangue do circuito extracorpóreo atingirão o coração em condiçōes de retroperfusão completamente despolarizado, podendo, quando emaltas doses, impregná-lo levando à diminuição da performance cardiaca até sua eliminaçāo.

Tendo especial tropismo pelo sistema nervoso, pode-se "anestesiar" o tecido de geração (nó sinusal) e condução dos estímulos cardíacos, levando à bradicardia após o desclampeamento aórtico.

Geralmente, nestes casos, é possível aumentar a freqüência cardiaca com a colocaçāo de um marcapasso atrial por 10 a 15 minutos, quando geralmente ocorre o retorno dos batimentos sinusais com freqüência adequada. A diminuição dos agentes anestésicos de longa duraçāo tem levado à diminuição acentuada destes fenômenos.

14 Esta técnica pode ser empregada em todos os casos de cirurgia cardíaca, devendo-se adaptar a técnica cirúrgica a seu emprego. Deve-se admitir maior quantidade de sangue no campo operatório, assim como uma certa turgência do coração. Interrupçōes de até 3 minutos não são críticas e facilitam a técnica em fases mais difíceis. A soma das interrupçōes não deve exceder 15 a 20 minutos, o que poderia levar à diminuição da performance cardíaca.

15 Quando os procedimentos sobre o coração estão terminados, retiramos a cânula de cardioplegia da raiz da aorta para que 0 ar das cavidades esquerdas seja totalmente eliminado pelo orifício da mesma através da própria infusão 
retrógrada e por clampeamento da drenagem venosa. Nestas condiçōes, desclampeamos a aorta e desconectamos a linha de infusão da retroplegia. O coração volta a bater em mais ou menos 10 segundos. Retiram-se a bolsa e a cânula do seio coronário e fecha-se a bolsa do átrio direito. Recolocamos a cânula da raiz da aorta para medida da pressão neste local e infusão da protamina.

16 A medida da pressão da raiz da aorta tem sido de grande valor para avaliação do paciente logo após saída de CEC. Geralmente, existe uma grande discrepância entre a mesma e a pressão da artéria radial, devido à vasoconstrição que, além disto, nos indica o uso de vasodilatadores.

17 Após 8 a 10 minutos, injetamos $5 \mathrm{ml} \mathrm{a} 10 \mathrm{ml}$ de cloreto de cálcio para reverter eventuais efeitos residuais da cardioplegia e após mais 5 a 10 minutos com redução progressiva do fluxo da bomba arterial, interrompe-se a circulação extracorpórea.

18 Em geral o desempenho cardíaco é excelente e raramente é necessário o emprego de drogas inotrópicas.

19 A diluiçāo com esta técnica é muito pequena pois, para um fluxo de cardioplegia final de $100 \mathrm{ml}$ por minuto durante 1 hora, empregam-se apenas $60 \mathrm{ml}$ de solução "mãe".

20 Com relação à hiperpotassemia, é raro que ocorra, uma vez que em 1 hora de clampeamento aórtico injetam-se, incluindo a induçāo, cerca de $100 \mathrm{mEq}$ de potássio, o que é uma quantia irrisória quando se compara com os $400 \mathrm{mEq}$ de potássio que existem no organismo.

De qualquer forma, logo após o desclampeamento aórtico, injetamos entre 20 a 40 unidades de insulina simples de acordo como peso do paciente. Para manter boa diurese durante a circulação extracorpórea e para baixar o potássio, pode-se empregar diuréticos como o furosemida, no próprio circuito extracorpóreo ou após a retirada de CEC.

\section{Condiçōes Especiais:}

a) se o coração volta a bater durante o período de manutençāo ou reperfusão, injetamos manualmente $0,5 \mathrm{ml} \mathrm{a} 1 \mathrm{ml}$ da solução de indução no circuito da cardioplegia através da torneira de três vias, que está incorporada ao sistema de infusão da solução "mãe";

b) se o coração apresentar ondulaçōes (como "ondas de um campo de trigo batido pelo vento"), injetamos $5 \mathrm{ml}$ de xilocaína $1 \%$ no circuito da cardioplegia pela mesma torneira de três vias. Este fenômeno nāo está ainda totalmente esclarecido, mas parece decorrer de alteraçōes da membrana celular com participação dos canais de sódio. De qualquer forma, as ondulaçōes, que têm sido raras com esta técnica, desaparecem com a xilocaína.

c) Se o coração continuar batendo com a infusão de $0,5 \mathrm{ml}$ a $1 \mathrm{ml}$ de solução de indução, podese manter o fluxo sangüíneo e aumentar em $50 \%$ o fluxo da soluçāo de manutenção/reperfusão por um período.

d) Geralmente o coraçāo fica parado durante todo o tempo, mas apresenta contração se fortemente estimulado. Chamamos a isto de coração quiescente, isto é, fica parado mas pronto para bater.

Acreditamos ser este o "ponto ideal" da cardioplegia. Se o coração fica muito flácido e nāo responde a estímulos fortes, podemos manter o fluxo sangüíneo da cardioplegia e diminuir a infusāo da soluçăo "mãe" de manutençāo/reperfusão em $50 \%$, voltando ao normal se o coração voltar a bater.

Desta forma, é possível manter a despolarização necessária sem exagerá-la.

22 Retroperfusão: tem sido muito discutida, pois parte do sangue infundido abandona as veias pelo sistema de Tebesius e parte é roubada pelos sinusóides. Quando se utilizam cânulas especiais de retroplegia introduzidas às cegas, autoinsufláveis ou não, ocorrem dois fenômenos:

a) existe uma grande perda de fluxo pelo seio coronário e é indispensável medir-se a pressão do sistema para avaliar se a perda não é muito grande.

b) é indispensável avançar a cânula para a veia interventricular anterior pois, se a mesma ficar no início do seio coronário, ela desloca-se com muita facilidade e perde muito fluxo para o átrio direito.

Acreditamos que a introduçāo de uma sonda de Foley, sob visāo direta contida por uma bolsa nas bordas do seio coronário, mantendo-a no início do sistema venoso coronariano, permite uma perfusāo retrógrada muito mais efetiva.

Disto decorre a diferença de fluxos por nós empregados e aqueles da literatura, os quais devem compensar as perdas naturais e aquelas decorrentes de má posição da cânula de retroperfusão. De qualquer forma, admite-se que apenas $25 \%$ do fluxo oferecido ao seio coronário antingem os óstios coronários na aorta.

Admitindo que necessitamos de $30 \mathrm{ml}$ de fluxo efetivo para manter a viabilidade de um cora- 
çăo de 300 gramas, a oferta de $100 \mathrm{ml}$ a 120 $\mathrm{ml}$ pelo seio coronário, seria mais que suficientes para suprir as necessidades.

23 Na cirurgia de coronária, às vezes é necessário interromper o fluxo da cardioplegia por 3 a 5 minutos. Sempre que isto ocorre, fazemos uma reperfusão com fluxo de $200 \mathrm{ml}$ por minuto por, pelo menos, 2 minutos antes de nova interrupção.

24 A utilização das seringas de infusāo elétrica permite a mistura do sangue com a solução "māe" em proporçōes muito precisas, o que é fundamental, uma vez que estas soluçōes são muito concentradas e qualquer erro leva a grandes desvios das concentraçōes desejadas. $\mathrm{Na}$ rotina utilizamos seringas de $20 \mathrm{ml}$.

Existe a possibilidade da utilizaçāo das bombas de infusāo de roletes, muito comuns em todos os hospitais, mas é necessário verificar qual o fluxo exato que as mesmas estāo enviando, quando se seleciona um determinado fluxo no painel. Temos encontrado variaçōes de até $25 \%$ entre o fluxo selecionado e o obtido, o que pode levar a diluiçōes inadequadas.

Mesmo com a utilizaçāo de seringas injetoras elétricas, é indispensáveis verificar se o fluxo indicado corresponde ao fluxo efetivamente fornecido.

Por outro lado, a bomba de roletes, que leva o sangue do oxigenador ao campo, deverá estar bem calibrada tanto com relaçāo à sua continência como também quanto ao fluxo fornecido, do contrário a proporçāo soluçāo "mãe"/sangue será incorreta e as concentraçōes finais, inadequadas.

25 É muito Importante que esta sistemática seja entendida em suas bases, de tal forma que o cirurgiāo e toda a equipe possam comunicarse com facilidade, sem os atropelos dos momentos críticos. Só a utilização do método na rotina permite seu amplo domínio. O emprego esporádico da técnica em casos graves certamente levará a complicaçōes decorrentes da falta de conhecimento dos detalhes, o que só será possível com a prática diária do método.

\section{RBCCV/44205-183}

BRAILE, D. M. - How to do it: Low volume backward normal thermic blood cardioplegia. Rev. Bras. Cir. Cardiovasc., 7(3):221-229, 1992.

DESCRIPTORS: myocardial protection, cardioplegia.

\section{REFERÊNCIAS BILBIOGRÁFICAS}

1 BRAILE, D. M.; ARDITO, R. V.; ZAIANTCHICK, M.; SANTOS, J. L. V.; SOARES, M. J. F. - Cardioplegia sangüínea contínua normotérmica. Rev. Bras. Cir. Cardiovasc., 4(2): 109-138, 1989.

BRAILE, D. M.; BUFFOLO, E.; ANDRADE, J. C. S.; VOLPE, M. A.; PALMA, J. H.; ZAIANTCHICK, M. Tratamento cirúrgico das patologias da aorta torácica utilizando parada circulatória total hipotérmica com perfusão cerebral retrógrada. (no prelo).

BOLLING, S. F.; FLAHERTY, J. T.; BULKLEY, B. H.; GOTT, V. L.; GARDNER, T. J. - Improved myocardial preservation during global ischemia by continuous retrograde coronary sinus perfusion. J. Thorad. Cardiovasc. Surg., 86: 659-666, 1983.
4 BRAZIER, J.; HOTTENROTT, C.; BUCKBERG, G. Noncoronary collateral myocardial blood flow. Ann. Thorac. Surg., 19: 426-435, 1975.

5 BUCKBERG, G. D. - Antegrade/retrograde blood cardioplegia to ensure cardioplegic distribution: operative techniques and objectives. J. Cardiac Surg., 4: 216-238, 1988.

6 BUCKBERG, G. D. - A proposed solution to the cardioplegic controversy. J. Thorac. Cardiovasc. Surg., 77: 803-817, 1979.

7 BUCKBERG, G. D.; Protean causes of myocardial stunning in infants and adults. J. Cardiac Surg., 8(Supl.): 214-219, 1993.

8 CHITWOOD, W. R.; SINK, J. D.; HILL, R. C.; 
WECHSLER, A. S.; SABISTON Jr., D. C. - The effects of hypothermia on myocardial oxygen consumption and transmural coronary blood flow in the potassiumarrested heart. Ann. Thorac. Surg., 190: 106-116, 1979.

9 LEVITSKY, S.; WRIGHT, R. N.; RAO, K. S.; HOLLAND, C.; ROPER, K.; ENGELMAN, R.; FEINBERG, H. Does intermittent coronary perfusion offer greater myocardial protection than continuous aortic crossclamping? Surgery, 82: 51-59, 1977.

10 ROSENKRANZ, E. R.; BUCKBERG, G. D.; LAKS, H.; MULDER, D. G. - Warm induction of cardioplegia with glutamate-enriched blood in coronary patients with cardiogenic shock who are dependent on inotropic drugs and intra-aortic balloon support. J. Thorac. Cardiovasc. Surg., 86: 507-518, 1983. 